work on the subject. He defined storage as the amount of a particular vitamin laid down in excess of the physiological level needed for normal functioning. From this point of view, the vitamins fall into two classes. The first group comprises those which occur in coenzymes or the prosthetic groups of enzymes, and for this group Dr. Kodicek proposed the name 'prosthetins'. Even with massive dosage, their concentration in the liver does not exceed a certain limit which probably represents saturation of the apoenzyme with the prosthetic group. Deficiency reduces the amount in the liver, but never to very low levels. These features are to be contrasted with the behaviour of the other group, the fat-soluble vitamins. Their concentration in the liver can be enormously increased by dosage (for example, to a hundred times the physiological level) or reduced to virtually zero by deficiency. The pattern of storage varies for the different fat-soluble vitamins. On dosage with vitamin A the efficiency of utilization can reach a maximum of 80 per cent of the amount fed, very high doses being toxic and leading to less efficient storage. By contrast, only a small fraction of administered vitamin $D$ is stored in the body, most of it in the liver. Vitamin $\mathrm{E}$ is mainly found in the body fat; but dosage with this vitamin leads to a temporary increase in the liver concentration. It has recently been shown by Dam and his colleagues that deposition of vitamin $\mathrm{K}$ in the livers of chicks occurs only in response to dosage with the natural vitamin and not after administration of vitamin $\mathrm{K}$ substitutes; this may have therapeutic importance.

Dr. J. Waterlow (University College of the West Indies) described his experiences with disorders of the liver found in tropical countries in association with malnutrition. The chief forms of liver disease which are common in tropical climates are fatty liver and cirrhosis ; massive necrosis is not more frequent than elsewhere. Fatty liver is found in very young children, and a severe form of fatty liver is a prominent feature of the kwashiorkor syndrome. The condition is nutritional in origin, probably the result of protein malnutrition in particular. In cases of fatty liver there is evidence of protein depletion, and Dr. Waterlow made the point that stigmata of protein insufficiency are not limited to the liver but are generalized, the organs most severely affected being those with the highest turnover of protein. Deposition of fat in the liver does not appear to be the fundamental factor determining the severity of the disease, which is probably dependent on the degree of protein depletion. The other common tropical liver condition, eirrhosis, does not appear to be an end-result of fatty infiltration, as has been demonstrated experimentally in rats. Geographically, there is little correspondence between the incidence of juvenile cirrhosis and of fatty livers in tropical countries. Dr. Waterlow suggested that juvenile cirrhosis may be produced by a combination of factors, one of which is malnutrition. Thus the occurrence of cirrhosis among West African children may result from a combination of malaria and malnutrition, the malnutrition being responsible for damage to the parenchymal cells and the malaria for overgrowth of fibrous tissue. In the West Indies the combination may be one of malnutrition and dietary toxins, arising from the widespread use of decoctions of plants ('bush tea').

The place of diet in the treatment of liver disease was discussed by Dr. A. L. Latner (Department of
Chemical Pathology, Royal Victoria Infirmary, Newcastle upon Tyne), who described the nutritional principles underlying such treatment. $\mathrm{He}_{\Theta}$ pointed out that, while a generous supply of protein in the diet is desirable for the regeneration of liver cells after the acute phase of liver damage is ended, the intravenous use of protein hydrolysates is irrational since the blood during severe liver damage already contains excessive amounts of amino-acids. There is, however, a good case for giving ample amounts of the vitamins. An interesting point made by Dr. Latner in this connexion was that the macrocytic anæmia associated with liver disease is relieved by folic acid but not by vitamin $B_{12}$. He also emphasized that liver diseases often cause profound disturbances of electrolyte metabolism which require correction. In acute liver failure Dr. Latner has obtained a high recovery rate by the intravenous use of glucose, saline, potassium chloride and massive doses of thiamine, nicotinamide and riboflavine, together with intramuscular injections of vitamins $\mathrm{E}$ and $\mathrm{K}$. The dietetic treatment of some less acute forms of liver disease was also described.

Dr. A. J. Hale provided a microscopical demonstration of the minute anatomy of the liver for those attending the meeting. The communications will be published in the Proceedings of the Nutrition Society.

H. N. MunRo

\section{THIRD INTERNATIONAL RUBBER TECHNOLOGY CONFERENCE}

$\mathrm{T}$ THE Third International Rubber Technology Conference, held in London at Church House, Westminster, during June 22-25, under the auspices of the Institution of the Rubber Industry, was attended by some six hundred and twenty delegates from eighteen countries. About seventy-five of the delegates were accompanied by their wives, for whom a separate social programme of visits to places of interest had been arranged.

In declaring the Conference open, its patron, the Marquess of Salisbury, who was introduced by the president of the Institution of the Rubber Industry, Lord Baillieu, welcomed the delegates on behalf of the British Government. He recalled that it was six years since the last Conference of this type, and that the matters to be discussed interested many parts of the world and would be concerned with such important matters as synthetic rubber, combinations of synthotic with natural rubber, and chemical modifications of natural rubber itself. After the official opening, the chair was taken by Dr. W. J. S. Naunton, the chairman of the Conference, who announced that there would be in all seven sessions, each having its sectional chairman, who would be a well-known authority on the subjects to be discussed. Fifty papers covering a wide range of subjects, some highly scientific and others purely technological, had been pre-printed and already circulated to the delegates. These papers had been selected from the ninety offered as being likely to provide a source of stimulating discussion.

The first session, under the chairmanship of Mr. E. A. Murphy, consisted of eight papers on the properties of natural rubber latex. The subjects discussed included the variability of Hevea latex, with 
particular reference to differences in the phosphate/ magnesium ratios of different clonal latices, and the structure of Hevea latex together with the influence of various chemical additives and treatments on its viscosity. Other papers dcalt with the effect of various naturally occurring mineral elements on field latex; and with the destabilization of ammoniated latex and soap-stabilized emulsions in the presence of complex zine diammine ions, which was suggested to be due to a decrease in hydration of the zinc diammine dilaurate, formed at the surface of the rubber particles. In an interesting paper E. W. Madge, H. M. Collier and J. L. M. Newnham described the study of viscosity changes in concentrated latex under different experimental conditions to determine the mechanism of the thickening of latex by zine oxide. Small variations in the amount of natural soap have been found to be of great importance. Other papers described the peptizing of rubber by the addition of organic mercaptans to fresh latex, the production of improved rubbers by the enzymatic deproteinization of skim latex and the occurrence of microgel in latex and sheet rubber.

Two periods were devoted to the second session for the discussion of nine papers on synthetic rubbers, the chair being taken by Dr. Naunton himself. A paper which aroused much interest was one in which G. F. Bloomfield, F. M. Merrett, F. J. Popham and. P. McL. Swift reported recent work on graft polymers derived from natural rubber, thus still further narrowing the gap between natural and synthetic rubbers and indicating how man may modify and sometimes improve naturally occurring high polymer hydrocarbons. A somewhat related paper by D. H. Coffey and 'T. J. Meyrick described the preparation and properties of condensation block copolymers of the polyester type. A paper entitled "How Synthetic Rubbers Affect You", by Mr. I. D. Patterson, described synthetic rubber progress in terms of a condensed time-scale and gave many interesting statisties of production and use, concluding with the apt quotation from Browning, "The best is yet to be". This paper provoked considerable discussion.

Prof. A. A. Morton, well known for his considerable work on the Wurtz reaction, presented a paper on the cation and anion influence in the 'Alfin' reagent for the polymerization of butadione. He substantiated his remarks by producing from butadiene and 'Alfin' catalyst a piece of synthetic rubber having a molecular weight of about ten million, the whole procedure taking less than five minutes, and in full view of the audience. Among newer types of synthetic rubbers described were those derived from butadieno copolymerized with unsaturated ketones and with 2-methyl-5-vinylpyridine, the last-mentioned type being capable of cross-linking by a 'quaternizing' reaction with organic halides. Other papers dealt with such subjects as the structure and solution properties of butadiene styrene copolymers of high molecular weight and the oil resistance of synthetic rubbers over periods up to fourteen years.

The next session, under the chairmanship of Dr. L. C. Bateman, was concerned with the chemistry of rubber. Six papers were introduced by their authors and covered a wide field, including such subjects as particle surface reactions, vulcanization by sulphur linkage and by atomic energy radiation, oxygen absorption, and chemical reactions of antioxidants used in vulcanized rubbor. A paper on infra-red spectroscopic analysis of elastomers was also discussed in this section.

In the session dealing with the physics of rubber, the chair was taken by Dr. J. R. Scott, and six papers were discussed, while in the case of two papers, the authors of which were not present, written comments or questions were invited. A wide variety of topics in this section included such subjects as permeability, reinforcement, elasticity, effect of nuclear magnetism, compounds for low-temperature service, elastic behaviour of filler-reinforced rubbers, dynamic properties and time-dependent effects in tyre cords.

The chairman for the session on developments in testing methods was Mr. J. M. Buist, and six papers were presented for comment and discussion. 'The first, by B. Pickup, described a new apparatus for assessing tear-down adhesion. F. F. Powell and S. W. Gough gave interesting information on the constant power principle in abrasion testing, while the paper by J. I. S. Williams and R. G. Clifton gave information on the methods of testing pneumatic tyres. Still other papers dealt with tyre cord fatigue, changes in electrical resistance with different black loadings, and a test for easily measuring the degree of vulcanization of rubber.

The sixth session (chairman, Dr. D. Parkinson) concerned itself with the theory and practice of compounding, and eight papers were delivered on many subjects, such as reinforcement by various means, oil-extending of natural rubber and the interaction of rubber and fillers during milling. As would be expected, several of the papers dealt with properties of various carbon blacks in rubber. An outstanding paper in this section was that by Dr. I. Drogin, who gave clearly and concisely a mass of detail on the properties of the various carbon blaclis.

The final session dealt with miscellaneous technology, with Dr. J. G. Mackay taking the chair. Four papers all concerned with, or related to, tyres were grouped in this section, the individual titles being as follows: abraded filament tyre cords; effect of heat setting on the physical properties of 'Terylene'; wave phenomena in tyres at high speed; and tread wear and fuel consumption of tyres.

An exhibition of instruments, selected principally to show some of the developments in rubber testing which have taken place since the last Conference, in 1948, was arranged in conjunction with the present Conference, there being seventy-six items, arranged in twelve groups. The organizations responsible for the development and manufacture of the instruments were indicated in the exhibition catalogue, and references to the literature were also given. In many cases, where appropriate, the instruments could be operated by turning a switch. The exhibition also contained a display of samples made from modified natural rubber, and a stand showing recent books dealing with rubber science and technology. Mr. B. J. A. Martin, who was responsible for the organization and arrangements of this exhibition, is to be highly commended for a most successful and interesting display. The proceedings of the Conference are to be published as a single volume, and the important task of collecting the many papers and discussions is in the capable hands of the editor-inchief, Mr. T. H. Messenger. There is no doubt that this volume, when issued, will form a valuable record of the 1954 Rubber Technology Conference.

F. A. JONES 